\title{
Novel Espin Actin-Bundling Proteins Are Localized to Purkinje Cell Dendritic Spines and Bind the Src Homology 3 Adapter Protein Insulin Receptor Substrate p53
}

\author{
Gabriela Sekerková, Patricia A. Loomis, Benjarat Changyaleket, Lili Zheng, Ron Eytan, Bin Chen, Enrico Mugnaini, and \\ James R. Bartles \\ Department of Cell and Molecular Biology, Feinberg School of Medicine and the Institute for Neuroscience, Northwestern University, Chicago, \\ Illinois 60611
}

We identified a group of actin-binding-bundling proteins that are expressed in cerebellar Purkinje cells (PCs) but are not detected in other neurons of the CNS. These proteins are novel isoforms of the actin-bundling protein espin that arise through the use of a unique site for transcriptional initiation and differential splicing. Light and electron microscopic localization studies demonstrated that these espin isoforms are enriched in the dendritic spines of PCs. They were detected in the head and neck and in association with the postsynaptic density (PSD) of dendritic spines in synaptic contact with parallel or climbing fibers. They were also highly enriched in PSD fractions isolated from cerebellum. The PC espins efficiently bound and bundled actin filaments in vitro, and these activities were not inhibited by $\mathrm{Ca}^{2+}$. When expressed in transfected neuronal cell lines, the PC espins colocalized with actin filaments and elicited the formation of coarse cytoplasmic actin bundles. The insulin receptor substrate p53 (IRSp53), an Srchomology 3 (SH3) adapter protein and regulator of the actin cytoskeleton, was identified as an espin-binding protein in yeast two-hybrid screens. Cotransfection studies and pull-down assays showed that this interaction was direct and required the N-terminal proline-rich peptide of the PC espins. Thus, the PC espins exhibit the properties of modular actin-bundling proteins with the potential to influence the organization and dynamics of the actin cytoskeleton in PC dendritic spines and to participate in multiprotein complexes involving SH3 domain-containing proteins, such as IRSp53.

Key words: espin; actin; cytoskeleton; cerebellum; Purkinje cell; dendritic spine; actin-bundling protein; postsynaptic density; IRSp53; SH3 domain

\section{Introduction}

Dendritic spines are dynamic components of the neuron that undergo changes in density or shape during development, learning, and disease and in response to hormones, neurotransmitters, and synaptic activity (Nimchinsky et al., 2002). Many of these changes reflect the dynamics of the dendritic spine actin cytoskeleton (Matus, 2000). Studies of live neurons indicate that dendritic spines undergo rapid actin-based movements (Fischer et al., 1998; Dunaevsky et al., 1999; Korkortian and Segal, 2001) and that a major portion of spine-associated actin is dynamic (Star et al., 2002). In cultured hippocampal neurons, glutamate receptor activation or electrical stimulation decreases actin-based spine movements (Fischer et al., 2000) and the fraction of dynamic spine actin (Star et al., 2002) but can also lead to the redistribution (Colicos et al., 2001) or loss (Halpain et al., 1998) of spine F-actin.

To understand the molecular mechanisms that underlie dendritic spine dynamics, it is important to identify the proteins that

Received Sept. 4, 2002; revised Nov. 14, 2002; accepted Dec. 4, 2002.

This work was supported by National Institutes of Health Grant DC04314 and Independent Scientist Award HD01210 (J.R.B.). We thank Dr. Anthony Frankfurter for providing tubulin antibody.

Correspondence should be addressed to Dr. James R. Bartles, Department of Cell and Molecular Biology, Ward Building 11-185, Feinberg School of Medicine, Northwestern University, 303 East Chicago Avenue, Chicago, IL 60611.E-mail: j-bartles@northwestern.edu.

Copyright $\odot 2003$ Society for Neuroscience $\quad 0270-6474 / 03 / 231310-10 \$ 15.00 / 0$ influence the actin cytoskeleton of dendritic spines and mediate its connection to the postsynaptic density (PSD). Efforts to identify the protein components of spines have focused on hippocampal neurons (Zhang and Benson, 2000; Hering and Sheng, 2001). Fewer such studies have examined the spines of cerebellar Purkinje cells (PCs). Implicated in motor control and cognitive functions (Hansel et al., 2001; Houk and Mugnaini, 2002; Molinari et al., 2002), PCs are rich in dendritic spines that receive excitatory input from two major sources. The spines of PC distal dendrites form synapses with $\sim 150,000-200,000$ parallel fibers, whereas the sparser spines of PC proximal dendrites form $\sim 1000-1500$ synapses with a single climbing fiber, resulting in one of the most powerful synaptic contacts in the brain (Strata et al., 2000; Hansel et al., 2001). There are indications that the spines and PSDs of PCs differ from those elsewhere in the CNS in ultrastructure, protein composition, and signaling pathways (Carlin et al., 1980; Araki et al., 1993; Brenman et al., 1996; Capani et al., 2001; Okubo et al., 2001, Miyagi et al., 2002).

We determined that the dendritic spines of PCs contain novel isoforms of the actin-bundling protein espin. Espins have been found previously in association with parallel actin bundles in Sertoli cell-spermatid junctions (Bartles et al., 1996; Chen et al., 1999), brush border microvilli (Bartles et al., 1998), and hair cell stereocilia (Zheng et al., 2000). [Espin should not be confused with epsin, an endocytic adaptor protein with a similar name (De Camilli et al., 2002).] Encoded by a single gene, espin isoforms 
share a C-terminal peptide that is necessary and sufficient for potent actin-bundling activity, but their N-terminal peptides contain different protein-protein interaction motifs as a result of differences in transcriptional initiation and splicing (Bartles, 2000). Here we report the localization of the novel PC espin isoforms, elucidate their sequences, and highlight their interactions with $\mathrm{F}$-actin and the insulin receptor substrate p53 (IRSp53), an Src homology 3 (SH3) adapter protein and known regulator of the actin cytoskeleton (Krugmann et al., 2001; Miki and Takenawa, 2002).

\section{Materials and Methods}

Animals. Young adult Sprague Dawley rats and CD-1 or CBA/CaJ mice were purchased from Harlan Sprague Dawley (Indianapolis, IN) or The Jackson Laboratories (Bar Harbor, ME). All experiments conformed to protocols approved by the Northwestern University Institutional Animal Care and Use Committee and Center for Comparative Medicine, an Association for Assessment and Accreditation of Laboratory Animal Care-accredited facility, and followed guidelines issued by the National Institutes of Health and the Society for Neuroscience.

Antibodies. Espin antibodies were produced in rabbits and affinity purified on columns of recombinant PC espin 1 or its N- or C-terminal fragments (Bartles et al., 1996; Chen et al., 1999). Rabbit polyclonal antibody to rat PSD-93/chapsyn-110 and mouse monoclonal actin antibody C4 were from Chemicon (Temecula, CA). Mouse monoclonal tubulin antibody TuJ1 was from Dr. Anthony Frankfurter (University of Virginia, Charlottesville, VA).

Immunolocalization in brain sections. For immunoperoxidase histochemistry, rodents were perfused transcardially with $4 \%$ formaldehyde in $0.12 \mathrm{~m}$ phosphate buffer, $\mathrm{pH} 7.4$, and brains were infiltrated with $30 \%$ sucrose. Frozen sections ( $30 \mu \mathrm{m}$ thick) were treated with $0.6 \% \mathrm{H}_{2} \mathrm{O}_{2}-$ $10 \%$ methanol and labeled with espin antibody or preimmune IgG. Bound antibody was visualized by the ABC method (Vector Laboratories, Burlingame, CA). Some labeled frozen sections were dehydrated, flat-embedded in Epon, and examined as $1-\mu \mathrm{m}$-thick sections. Images were obtained with a Spot RT CCD camera and Nikon (Melville, NY) Eclipse 800 microscope. Some frozen sections were labeled with espin antibody and tubulin antibody, followed by Alexa488- and Alexa594labeled goat secondary antibodies or phalloidin (Molecular Probes, Eugene, OR), and optical z-sections (1.5 $\mu \mathrm{m}$ thick) were obtained using a Nikon microscope with a PCM 2000 confocal laser scanning system. For labeling at the electron microscopic level, rats were perfused with $4 \%$ formaldehyde (with or without $0.1 \%$ glutaraldehyde) in $0.12 \mathrm{M}$ phosphate buffer, $\mathrm{pH}$ 7.4. Brain sections $(60 \mu \mathrm{m}$ thick) were cut on a Vibratome, cryoprotected with glycerol-dimethylsulfoxide mixtures, frozen and thawed four times, treated with $1 \%$ sodium borohyride, followed by $0.6 \% \mathrm{H}_{2} \mathrm{O}_{2}-10 \%$ methanol, and labeled with espin antibody or preimmune IgG. Bound antibody was visualized by the peroxidase-antiperoxidase method (Sternberger Immunochemicals, Lutherville, MD). Sections were treated with $2 \% \mathrm{OsO}_{4}$ and $1 \%$ uranyl actetate, dehydrated, and flat-embedded in Epon. Ultrathin sections were counterstained with uranyl acetate and lead citrate and examined on a Zeiss (Thornwood, NY) EM10 electron microscope at $80 \mathrm{kV}$.

Subcellular fractionation and Western blot analysis. PSDs were isolated from rat cerebellum by subcellular fractionation in the presence of $1 \mathrm{~mm}$ phenylmethylsulfonyl fluoride, $1 \mu \mathrm{g} / \mathrm{ml}$ antipain, and $1 \mu \mathrm{g} / \mathrm{ml}$ leupeptin using the modified method of Carlin et al. (1980) followed by Dosemeci and Reese (1993). Proteins were detected on Western blots using the ECL method (Amersham Biosciences, Arlington Heights, IL). In some experiments, a modified PSD fraction, prepared using only a single extraction with $0.5 \%$ Triton X-100, was subjected to additional extraction (Cho et al., 1992).

PCR, DNA sequence analysis, mutagenesis, and cloning. The sequences of the PC espin isoforms were inferred by DNA sequence analysis of overlapping PCR products resulting from reverse transcription (RT)PCR and $5^{\prime}$ rapid amplification of cDNA ends (RACE)-PCR reactions conducted using RNA isolated from rat and mouse cerebellum and selected espin primers in conjunction with kits and reagents purchased from Invitrogen (Carlsbad, CA). Full-length cDNAs for the rat PC espins and rat $\mathrm{PC}$ espin 1 deletion constructs missing the $\mathrm{N}$-terminal (96-SSLPPPPPPSFPPPPPGTQLPPPPGTPAPNPPVGL-132 for $\delta 1$ ) or C-terminal proline-rich peptide (256-PPPPPPPPLPEALSSPPPAPPLPIEG-281 for $\delta 2$ ) were prepared by ligating selected restriction fragments. A near full-length cDNA encoding the short form of mouse IRSp53 (GenBank accession number BC016411) was obtained in yeast two-hybrid screens (see below). A cDNA encoding the 186 amino acid C-terminal peptide (M367-R552) of the long form (transcript variant 2) of human IRSp53 (GenBank accession number NP_059345) was obtained from HeLa cell RNA by RT-PCR.

Yeast two-hybrid screens. Screening was performed using the Clontech Matchmaker GAL4 System 2 (BD Biosciences Clontech). A cDNA encoding the N-terminal portion of rat PC espin 1 (D13-Q421), which included the two proline-rich peptides, was fused in-frame to the GAL4 binding domain of the pAS2-1 vector and used as "bait" to screen Clontech Matchmaker pACT2 cDNA libraries from mouse brain and testis in Y190 yeast cells. His ${ }^{+}$transformants were confirmed through a second round of growth on selection plates and a $\beta$-galactosidase filter assay.

Bacterial expression, purification, and characterization of recombinant proteins. PC espin isoforms were expressed in Escherichia coli BL-21 Star (DE3) with a short $(\sim 1.5 \mathrm{kDa}) \mathrm{N}$-terminal $6 \times$ His tag using the ProEXHTa vector (Invitrogen), affinity purified from soluble bacterial extracts under nondenaturing conditions on Ni-NTA agarose (Qiagen, Valencia, CA), dialyzed against assay buffer, and clarified by ultracentrifugation before use (Bartles et al., 1998; Chen et al., 1999). Cosedimentation F-actin-bundling assays were performed as described previously (Bartles et al., 1998; Chen et al., 1999). For pull-down assays, the 186 amino acid C-terminal peptide of human IRSp53, which includes its SH3 domain, was expressed as a glutathione $S$-transferase (GST) fusion protein using the pGEX4T-3 vector (Amersham Biosciences). Recombinant rat $\mathrm{PC}$ espin proteins were incubated with glutathione-Sepharose $4 \mathrm{~B}$ beads preloaded with GST-IRSp53 SH3 domain fusion protein or GST alone in $0.1 \mathrm{M} \mathrm{KCl}, 20 \mathrm{~mm}$ imidazole- $\mathrm{HCl}, 1 \mathrm{~mm}$ DTT, and $1.5 \mathrm{~mm}$ $\mathrm{NaN}_{3}, \mathrm{pH} 7.4$, for $1 \mathrm{hr}$ at $4^{\circ} \mathrm{C}$. After washing four times at $13,000 \times \mathrm{g}$ for $30 \mathrm{sec}$, the bound proteins were released by heating in SDS and resolved in SDS gels.

Cell transfection. Cells of the mouse Neuro-2a neuroblastoma line (American Type Culture Collection, Manassas, VA) were cultured in DMEM containing $10 \%$ fetal bovine serum and differentiated by culturing in DMEM containing 2\% fetal bovine serum and $0.5 \mathrm{~mm}$ dibutyrylcAMP (Sigma, St. Louis, MO) for 1-11 d (Wu et al., 1998). Twenty-four hours before transfection, cells were trypsinized and replated on coverslips coated with poly-L-lysine (Sigma) followed by laminin. Transient transfection with Lipofectamine (Invitrogen), fixation, immunolabeling, and examination by fluorescence microscopy were performed as described previously (Chen et al., 1999) using a Zeiss Axioplan 2 Imaging microscope system equipped with an Axiocam digital camera. The PC espins and the mouse IRSp53 construct were expressed using pEGFP-C vectors (BD Biosciences Clontech) and detected as green fluorescent protein (GFP) fusions. For cells examined $8 \mathrm{hr}$ after transfection, the signal was boosted using GFP monoclonal antibody (Roche, Indianapolis, IN), followed by Alexa488-secondary antibody (Molecular Probes). For cotransfections, untagged PC espins were expressed using the pcDNA3 vector (Invitrogen). Multiple labeling for F-actin and DNA were performed with using Texas Red-phalloidin or 4',6-diamidino-2phenylindole (Sigma), respectively.

\section{Results}

\section{Localization of espin isoforms in cerebellum}

When frozen sections of rat or mouse brain were labeled with affinity-purified rabbit polyclonal espin antibodies, intense specific immunostaining was observed in the cerebellar cortex (Fig. $1 A, B$ ) but was absent in cerebral cortex, hippocampus, striatum, and brainstem. The dark diaminobenzidine (DAB) reaction product occupied the PC and molecular layers of the cerebellar cortex, whereas the granular layer and white matter were free of staining (Fig. 1A,B). When immunoperoxidase-labeled frozen 


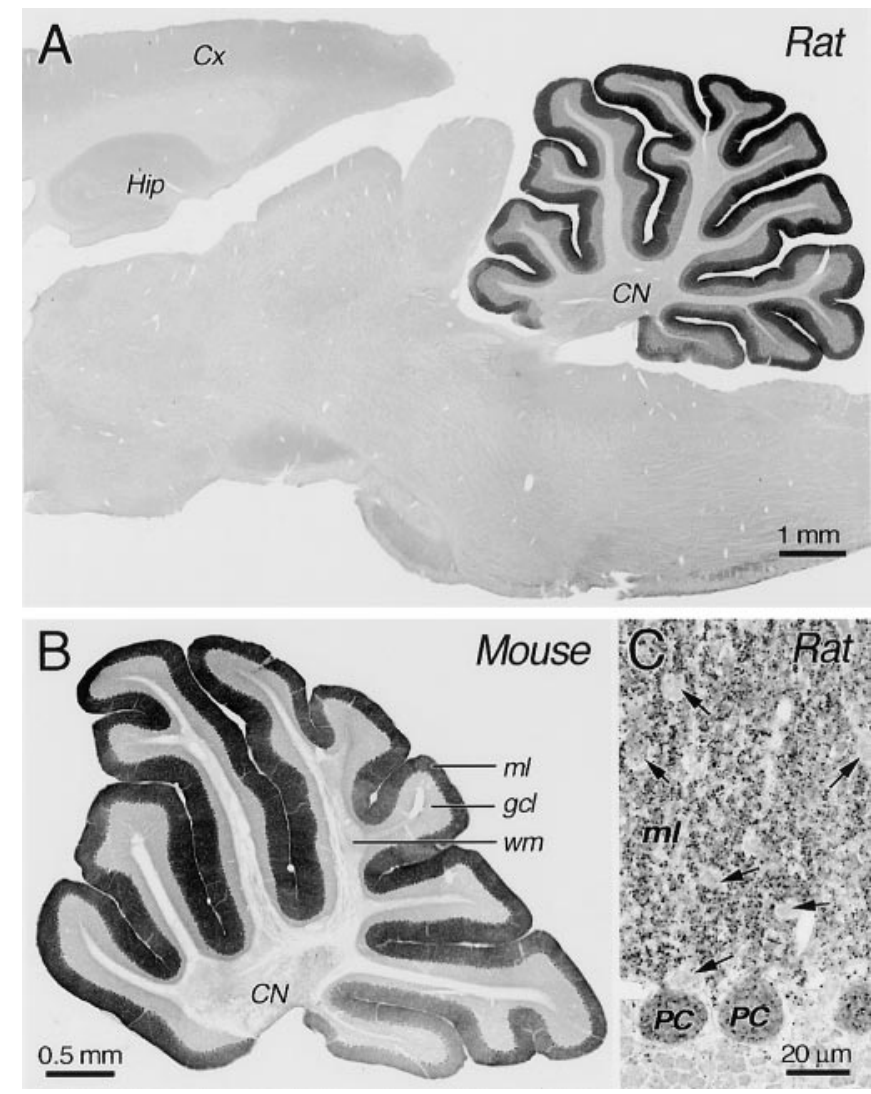

Figure 1. Immunoperoxidase localization of espins to the $\mathrm{PC}$ and molecular layers of the cerebellar cortex at the light microscopic level. $A$, In this frozen section of rat brain, the dark DAB reaction product is restricted to the cerebellar cortex. The cerebral cortex $(C X)$, hippocampus (Hip), cerebellar nuclei $(C N)$, and other brain regions are not stained. $B$, The pattern of immunostaining in frozen sections of mouse cerebellum is identical to that of rat and is confined to the $\mathrm{PC}$ layer and molecular layer $(\mathrm{ml})$. The granule cell layer $(g \mathrm{gl})$, white matter $(w m)$, and cerebellar nuclei $(C N)$ are not stained. $C$, Diffuse staining of $P C$ body $(P C)$ and stem dendrites and a dense punctate staining of the molecular layer $(\mathrm{m} / \mathrm{l})$ are shown in this $1-\mu \mathrm{m}$-thick section cut from an immunoreacted frozen section of rat cerebellum embedded in Epon. Stellate and basket cells (arrows) are not stained.

sections of rat cerebellum were embedded in plastic and analyzed as $1-\mu \mathrm{m}$-thick sections, the DAB reaction product was detected as dark puncta, $\sim 1 \mu \mathrm{m}$ in diameter, distributed densely over the molecular layer and as a weaker diffuse staining in the cell bodies and stem dendrites of PCs but not in their axons (Fig. $1 B, C$ ). The density of puncta over the molecular layer was estimated to be $\sim 2.5$ - to 3-fold higher than over the cell bodies of PCs. No other cell types were labeled, including the granule and Golgi cells of the granular layer and the stellate and basket cells of the molecular layer. Therefore, these results suggested that PCs were the only cerebellar cell type containing espins and that the PC espins were enriched in PC dendritic spines.

A dense punctate staining of the molecular layer was also observed when espins were localized by confocal immunofluorescence (Fig. $2 \mathrm{~B}$ ). Consistent with a localization to PC dendritic spines, the espin-positive puncta showed extensive overlap with F-actin-rich puncta as revealed by double labeling with fluorescent phalloidin (Fig. 2A-C). Moreover, double labeling for espin and tubulin showed an enrichment of espin in tiny $(\sim 1 \mu \mathrm{m})$, gemmule-shaped projections studding the tubulin-positive shafts of PC spiny branchlets (Fig. 2D,E). The level of espin antibody staining appeared consistently intense in the heads of the spines.

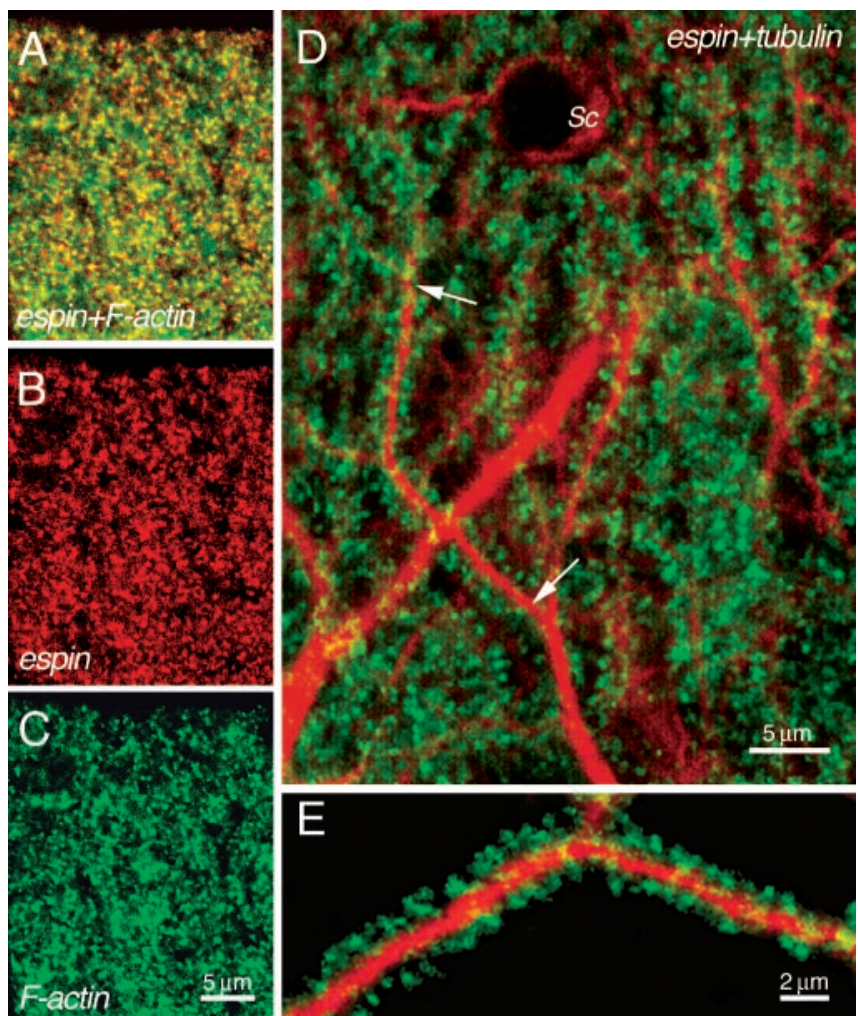

Figure 2 Immunofluorescence localization of espins to $P($ dendritic spines by laser confocal microscopy. $A-C$, Frozen section of rat brain labeled with espin antibody $($ red; $B)$ and fluorescent phalloidin ( green; $C$ showing molecular layer of the cerebellar cortex. Note the extensive overlap ( yellow; $A$ ) of the puncta that are espin positive $(B)$ and the puncta that contain F-actin (C).D,E, Frozen section of rat brain labeled with espin antibody ( green) and tubulin antibody (red). D, This field of PC dendrites in the superficial half of the molecular layer includes several spiny branchlets (red) covered with espin-positive spines ( green). A tubulin-positive stellate cell body $(S c)$ with an emerging dendrite is also evident. $E$, To highlight the relationship between the espin-positive spines and tubulin-positive dendritic shaft, the segment of $P($ spiny branchlet demarcated by arrows in $D$ is shown here (rotated $90^{\circ}$ ) after digitally erasing the surrounding tissue in Photoshop (Adobe Systems, San Jose, CA).

Espin localization at the electron microscopic level definitively confirmed immunostaining of PC dendritic spines (Fig. 3). Dendritic spines containing DAB reaction product were involved in synapses with either parallel fibers (Fig. $3 B, C$ ) or climbing fibers (Fig. 3D). After fixation with $4 \%$ formaldehyde and moderate permeabilization of the Vibratome sections by repeated freezing and thawing before immunolabeling, the majority of PC spines stained positively for espin (Fig. $3 A$ ). In these sections, the PSD, subsynaptic globules, and tubules of the endoplasmic reticulum in the head and neck were stained components of the spines (Fig. $3 A, B$ ). Little staining was detected in the dendritic shaft. Addition of even small amounts $(0.1 \%)$ of glutaraldehyde to the fixative resulted in a sharp decline in immunostaining, causing it to appear more restricted to the PSD (Fig. 3C,D). The conspicuous labeling of the PSD was remarkable, although it is well known that the DAB reaction product can diffuse locally within the $\sim 1$ $\mu \mathrm{m}$-thick spine. Attempts to localize PC espins by postembedment immunogold labeling of ultrathin sections prepared using LR White (Bartles et al., 1998) or the freeze-substitution Lowicryl embedding method (Landsend et al., 1997; Roche et al., 1999) were not successful, presumably attributable to epitope masking or inactivation. We were, however, able to obtain independent biochemical evidence in support of the localization of PC espins to the PSD using subcellular fractionation (see below). 

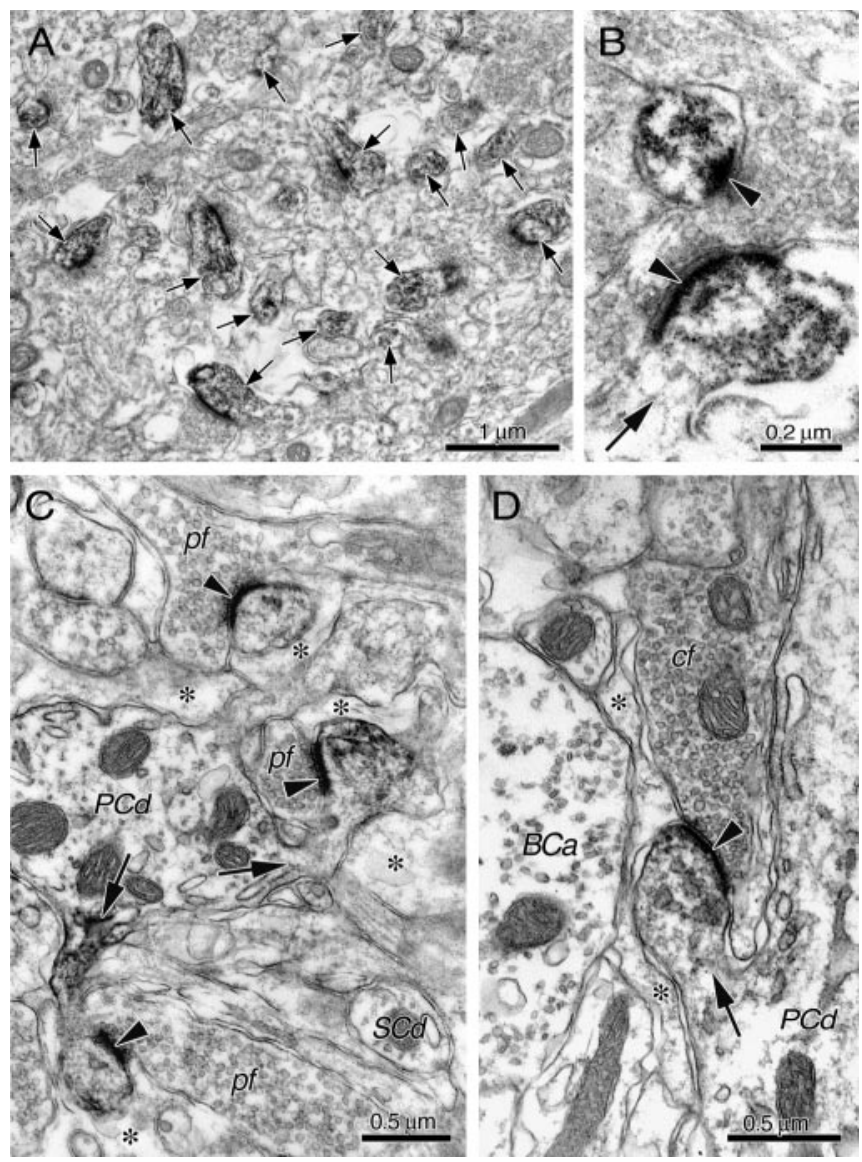

Figure 3 Immunoperoxidase localization of espins to $\mathrm{PC}$ dendritic spines by electron microscopy. Rat brains were fixed with either $4 \%$ formaldehyde $(A, B)$ or $4 \%$ formaldehyde and $0.1 \%$ glutaraldehyde $(C, D)$. $A$, Arrows designate multiple examples of espin-positive $P C$ spines. $B$, Two espin-positive $P C$ spines in synaptic contact with a single axonal ending are shown at higher magnification. Espin antibody staining is detected in association with the PSD (arrowheads), in subsynaptic globules situated beneath the PSD, and around elements of endoplasmic reticulum in the cytoplasm of the spine head. An arrow points to the neck region of the lower spine. C, A PC spiny branchlet ( $P C d$ ) emits espin-positive spines (arrowheads) in synaptic contact with parallel fiber varicosities ( $p f)$. Arrows point to the neck region of two spines. Asterisks, Processes of astrocytic Bergmann glia. SCd, Stellate cell dendrite. D, An espin-positive spine arising from a primary $P C$ dendrite $(P C d)$ forms a synaptic contact with a climbing fiber varicosity $(c f)$. The arrowhead indicates the densely stained PSD, and the arrow indicates the spine neck. Asterisks, Processes of astrocytic Bergmann glia. BCa, Basket cell axon terminal containing pleomorphic synaptic vesicles.

\section{Molecular characterization of PC espin isoforms}

Western blot analysis using affinity-purified espin antibodies showed the presence of multiple immunoreactive polypeptides in cerebellum. Intense specific labeling of a poorly resolved doublet at $60-65 \mathrm{kDa}$ was observed in homogenate of rat cerebellum (Fig. 4 A). A minor band at $\sim 53 \mathrm{kDa}$ was also labeled specifically. The pattern of specific labeling for mouse cerebellar homogenate showed a major band at $\sim 68 \mathrm{kDa}$ and a poorly resolved multiplet at $55-60 \mathrm{kDa}$ (Fig. 4A). No specific labeling was detected in homogenate of cerebral cortex (Fig. 4A).

The multiplicity of bands observed on Western blots appeared to be attributable to the presence of multiple espin isoforms in PCs. Sequence analysis of cDNAs obtained by RT-PCR and 5' RACE-PCR using espin primers revealed the presence of transcripts for four novel espin isoforms in RNA isolated from cerebellum (GenBank accession numbers AF540942-AF540945 for mouse and AF540946-AF540949 for rat). The stick-figure diagram in Figure $4 B$ summarizes the structural relationships be-
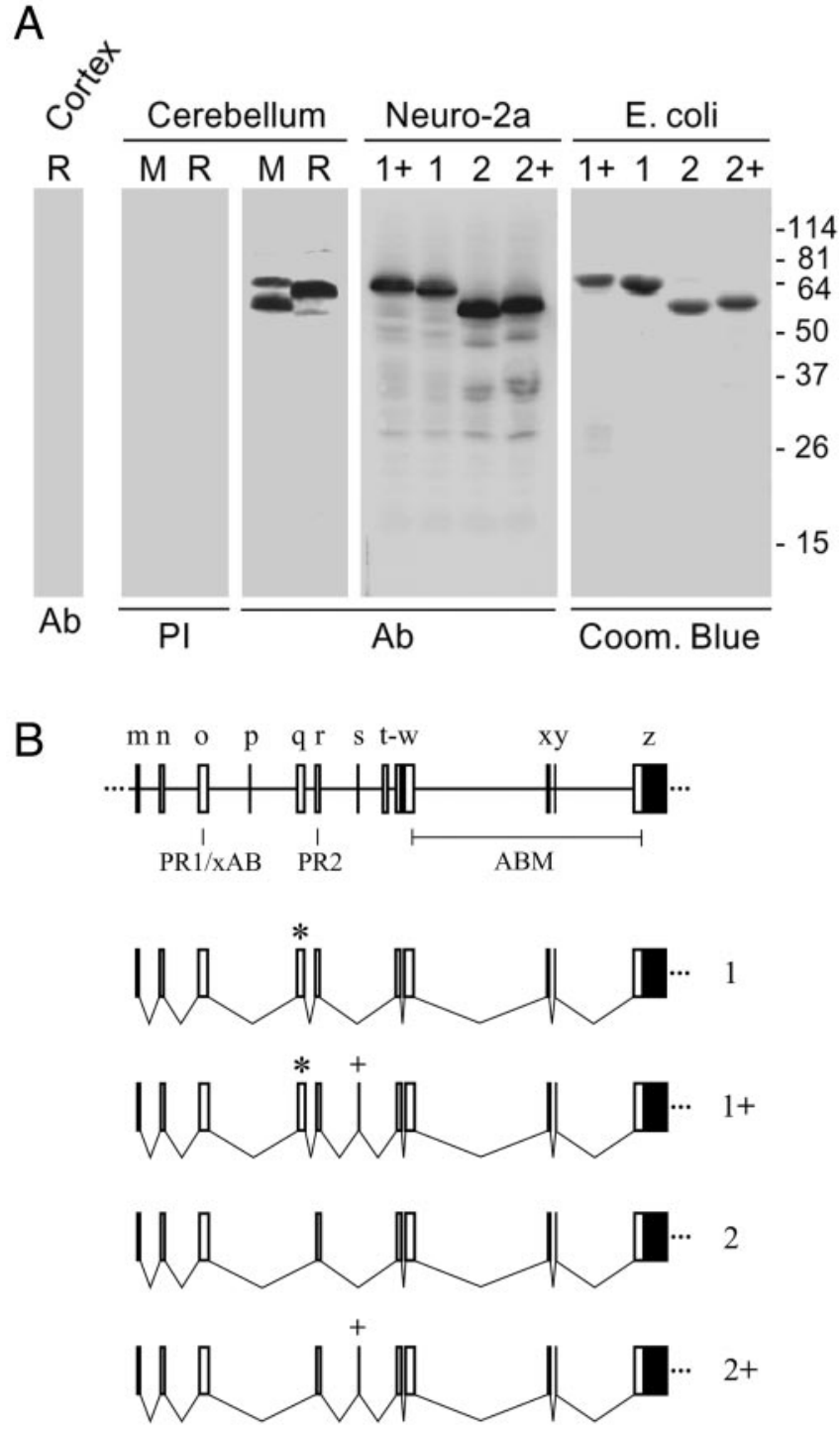

Figure 4 Western blot detection and sequences of multiple PC espin isoforms. A, Western blot detection of multiple espin isoforms in mouse and rat cerebellum and comigration with proteins expressed by $C D N A$ s encoding the four rat $P C$ espin isoforms. Western blot containing mouse $(M)$ and rat $(R)$ cerebellar homogenate (Cerebellum) labeled with espin antibody ( $A b)$ shows multiple bands in the $53-68 \mathrm{kDa}$ range. These bands are not detected in homogenate of rat cerebral cortex (Cortex) or when blots of cerebellar homogenate are labeled with preimmune IgG $(P I)$. CDNAs encoding the four rat $P C$ espin isoforms $(1+, 1,2$, or $2+)$ elicit the expression of proteins with similar electrophoretic mobilities in mouse Neuro-2a neuroblastoma cells (Neuro-2a; Western blot of transfected cells) or in bacteria [E. coli; Coomassie blue (Coom. Blue)-stained gel of affinity-purified proteins bearing short N-terminal $6 \times$ His tag]. The positions of molecular mass markers are shown at the right in kilodaltons. $B$, Exon maps revealing the novel transcription start site and differential splicing of the four PC espin isoforms. The top is a map of an $\sim 18 \mathrm{~kb}$ segment of the mouse espin gene showing the relative sizes and positions of the known exons $(m-z)$. Exons $w-z$ encode the $(-$ terminal actin-bundling module $(A B M)$, a peptide necessary and sufficient for actin-bundling activity in vitro that is shared among known espin isoforms. Exon 0 encodes the $\mathrm{N}$-terminal proline-rich peptide (PR1) and the additional F-actin-binding site $(X A B)$. Exon rencodes the C-terminal proline-rich peptide (PR2). The bottom shows how the exons are joined to make the designated $\mathrm{PC}$ espin isoform $(1,1+, 2$, or $2+)$. The novel transcription start site of the $P C$ espins is encoded by exon $m$. Differential splicing of exons $q$ (asterisks) and s ( plus signs) account for a total of four sequence permutations. Exons $p, t$, and $v$ are not included in any $\mathrm{PC}$ espin isoform. Exon $p$ is present in mouse Sertoli cell espin. Exons $t$ and $v$ are specific to mouse small espin. Only part of the $3^{\prime}$-UTR ( filled box encoded by exon $z$ ) is shown. 
tween these four espin isoforms, which we designated PC espins $1,1+, 2$, and $2+$. It also includes an updated map of the mouse espin gene showing the relative positions and sizes of known exons. Mouse and rat counterparts were $92-93 \%$ identical at the amino acid sequence level. The C-terminal peptides of all four PC espins (encoded by exons $\mathrm{w}-\mathrm{z}$ ) were identical to those of the other espin isoforms characterized to date (Chen et al., 1999), but their $\mathrm{N}$ termini were different. Overall, their $\mathrm{N}$ termini more closely resembled that of the $\sim 110 \mathrm{kDa}$ Sertoli cell espin isoform (Bartles et al., 1996) than the $\sim 30 \mathrm{kDa}$ small espin isoform of enterocytes and renal proximal tubular epithelial cells (Bartles et al., 1998). For example, all four PC espin isoforms contained the two proline-rich peptides (exons o and $r$ ) and the additional F-actin-binding peptide (exon o) just downstream of the $\mathrm{N}$-terminal proline-rich peptide. However, in place of the ankyrin-like repeats found at the $\mathrm{N}$ terminus of Sertoli cell espin (Bartles et al., 1996), the PC espins contained a unique 3 amino acid peptide (initiator methionine plus two additional amino acids) encoded, along with the 5 '-untranslated region (UTR), by exon $\mathrm{m}$. In addition, the PC espins were missing the short peptide encoded by exon p. Two of the isoforms, PC espin 2 and $2+$, were missing the peptide between the two proline-rich peptides encoded by exon q (Fig. 4B, asterisks), thereby bringing the two proline-rich peptides closer together in primary sequence. Finally, two of the isoforms, one with and one without the peptide encoded by exon q, contained an additional 9 amino acid peptide rich in positively charged amino acids (KVRVLRHRK in mouse and KVRILRHRK in rat) encoded by small exon s (Fig. $4 B$, plus signs) and hence were designated $\mathrm{PC}$ espins $1+$ and $2+$, respectively.

To clarify the relationship between cDNA sequence and apparent molecular mass, rat versions of all four PC espin isoforms were expressed in untagged form in transiently transfected cells of the mouse Neuro-2a neuroblastoma line and also in $E$. coli with a short $(\sim 1.5 \mathrm{kDa}) \mathrm{N}$-terminal $6 \times$ His tag (Fig. $4 A)$. Regardless of expression system, the rat PC espin proteins migrated in SDS gels in the same general region in which the immunoreactive bands were detected on Western blots of cerebellum (Fig. 4A). The minor bands detected at lower positions on the Western blot of the transfected Neuro-2a cells represent proteolytic breakdown products. Ignoring the effects of posttranslational modification, these comparisons suggested that the $\sim 60 \mathrm{kDa}$ PC espin 1 and, to a lesser extent, the $\sim 65 \mathrm{kDa}$ PC espin $1+$ were the two major espin isoforms present in rat cerebellum. Only small amounts of proteins comigrating with the expressed rat PC espins 2 or $2+$ were detected on the Western blots of rat cerebellum. A different outcome was obtained for the mouse, whose PC espin isoforms are predicted to be $\sim 2 \mathrm{kDa}$ larger than their rat counterparts attributable to minor differences in amino acid sequence. More than one-half of the label detected on the Western blots of mouse cerebellum migrated at the lower molecular mass (55-60 $\mathrm{kDa}$ ) expected for mouse PC espins 2 and $2+$. In agreement with this trend toward increased expression of PC espin 2 and $2+$ proteins in the mouse, RT-PCR analysis of cerebellar RNA showed a greater relative abundance of transcripts encoding PC espins 2 and $2+$ in mouse than in rat (data not shown).

\section{Actin binding and bundling by PC espins in vitro}

Consistent with the presence of the C-terminal peptide shared among known espin isoforms and the additional F-actin-binding site encoded by exon o (Chen et al., 1999), all four PC espin isoforms efficiently bound and bundled preformed actin filaments in vitro under physiological buffer conditions. These re-
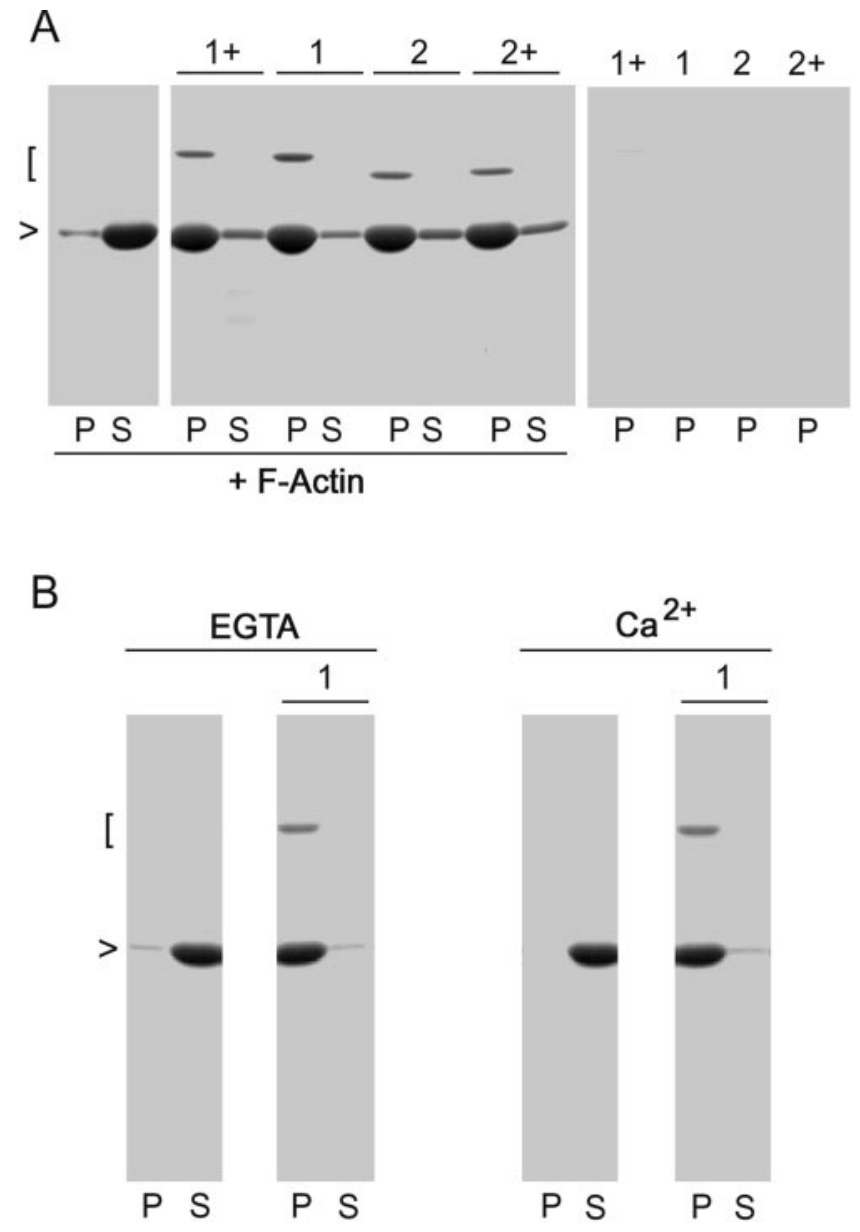

Figure 5 Efficient actin binding and bundling by all four PC espin isoforms and insensitivity to $\mathrm{Ca}^{2+} . A$, When incubated with preformed actin filaments at ratios of 1 espin for every 15-20 actin monomers, each rat $P C$ espin isoform $(1+, 1,2$, or $2+)$ shifts the majority of the actin $(>)$ from the supernatant $(S)$ to the pellet $(P)$, which is indicative of efficient actin bundle formation in this cosedimentation assay. The recovery of $P($ espins (bracket) in the pellet in the presence of actin filaments ( $+F$-Actin), but not in their absence (right panel), is indicative of high-affinity binding to $\mathrm{F}$-actin. $B$, No differences are observed in the ability of rat $P C$ espin 1 ( 1 and bracket) to shift the F-actin $(>)$ from the supernatant $(S)$ to the pellet $(P)$ or to be recovered with $\mathrm{F}$-actin in the pellet when the cosedimentation assay is conducted in the presence of $1 \mathrm{~mm}$ EGTA to chelate $\mathrm{Ca}^{2+}\left(\right.$ EGTA) or in the presence of $20 \mu \mathrm{M} \mathrm{CaCl}\left(\mathrm{Ca}^{2+}\right)$.

sults are illustrated in Figure $5 \mathrm{~A}$ using a standard cosedimentation actin-bundling assay. When preformed actin filaments were incubated in the absence of espins and then centrifuged at medium speed, $>95 \%$ of the preformed actin filaments remained in the supernatant. In contrast, when even very low amounts of the PC espin isoforms were mixed with the preformed actin filaments (in this case, only $\sim 1$ espin for every 15-20 actin monomers), most of the actin filaments were recovered in the pellet. This shift of F-actin from the supernatant to the pellet in this assay is indicative of actin bundle formation (Bartles et al., 1998; Chen et al., 1999). From this assay, it was also apparent that all four PC espin isoforms bound efficiently to actin filaments. In the presence of F-actin, the PC espins were quantitatively recovered in the pellet, but, in the absence of F-actin, they remained soluble and were not detected in the pellet (Fig. 5A). Actin bundle formation was also noted in these mixtures by increases in solution turbidity and by negative staining electron microscopy (data not shown), which confirmed the presence of copious actin bundles resembling the partially ordered parallel actin bundles elicited by other espin 

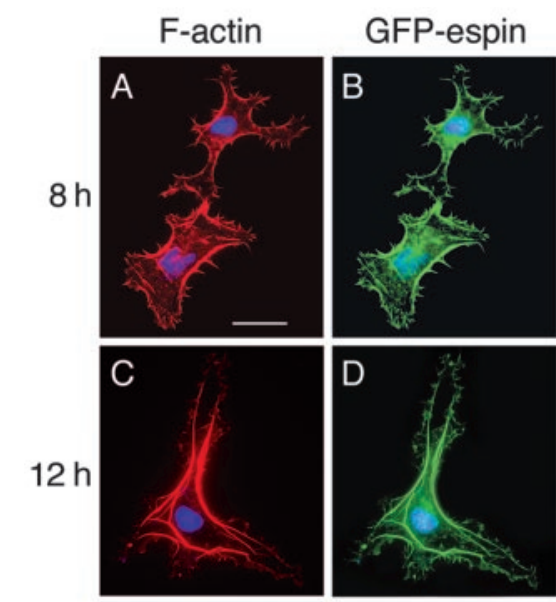

$24 \mathrm{~h}$
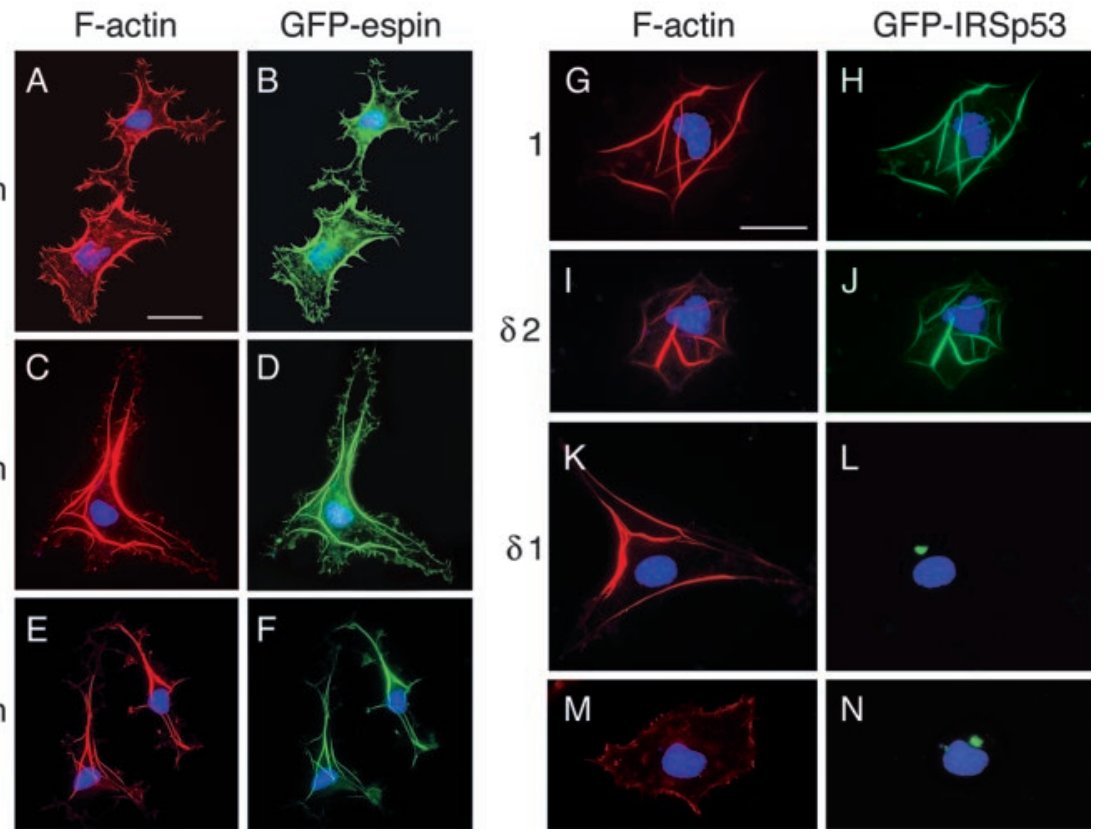

Figure 6. Colocalization of PC espins, F-actin, and IRSp53 in transfected mouse Neuro-2a neuroblastoma cells. Cell nuclei labeled with 4',6-diamidino-2-phenylindole are shown in blue. A-F, Cells transfected with GFP PC-espin 1 ( green) and labeled for actin filaments with Texas Red-phalloidin (red). At early times after transfection $(8 h ; A, B)$, the GFP-PC espin and F-actin are colocalized in filopodia and arcs beneath some concave margins. The green fluorescent signal of these cells was boosted with GFP antibody and Alexa488-labeled secondary antibody. Scale bar (in A), $25 \mu \mathrm{m}$. At later times after transfection $(12 h ; C, D)$, the GFP-PC espin and F-actin remain colocalized, but labeling in filopodia progressively diminishes as coarse cytoplasmic espin/F-actin bundles become the dominant labeled structure (see also $G$ ). In cells displaying a differentiated neuronal morphology $(24 h ; E, F)$, the coarse cytoplasmic espin/F-actin bundles are frequently present in large-diameter neurites. $G-N$, Cells cotransfected with GFP-IRSp53 ( green) and full-length or mutated PC espin 1 and labeled for F-actin with Texas Red-phalloidin (red). G-J, Cells expressing GFP-IRSp53 in conjunction with either rat $\mathrm{PC}$ espin $1(1 ; G, H)$ or rat $\mathrm{PC}$ espin 1 missing its $C$-terminal proline-rich peptide $(\delta 2 ; I, J)$ show extensive colocalization of GFP-IRSp53 to the coarse cytoplasmic espin/F-actin bundles elicited by the PC espin. Scale bar (in G), $20 \mu \mathrm{m} . K$, L, Cells expressing GFP-IRSp53 in conjunction with rat PC espin 1 missing its N-terminal proline-rich peptide $(\delta 1)$ still contain coarse cytoplasmic espin/F-actin bundles $(K)$, but the GFP-IRSp53 does not colocalize to the bundles. Instead, it accumulates at lower levels in a dense perinuclear aggregate ( $L$ ). $M, N$, Cells expressing GFP-IRSp53 without PC espin do not contain coarse cytoplasmic actin bundles $(M)$ and also show relatively low levels of GFP-IRSp53 accumulation in a dense perinuclear aggregate $(N)$.

isoforms (Bartles et al., 1998; Chen et al., 1999). Unlike other proteins with actin-bundling activity, such as villin and fimbrin (Glenney et al., 1981; Alicea and Mooseker, 1988; Namba et al., 1992; Lin et al., 1994), the espins appear not to be inhibited by $\mathrm{Ca}^{2+}$. This result is illustrated in Figure $5 B$ for rat PC espin 1, which shows no difference in the ability to bind and bundle F-actin in cosedimentation assays conducted in the presence of EGTA (to chelate any trace $\mathrm{Ca}^{2+}$ that might be present in the buffer) or $20 \mu \mathrm{M} \mathrm{CaCl}_{2}$. Similar results were obtained with using all four $\mathrm{PC}$ espin isoforms and for $\mathrm{CaCl}_{2}$ concentrations as high as $100 \mu \mathrm{M}$ (data not shown).

\section{PC espins in transiently transfected neuronal cell lines}

To examine the localization and effects of the PC espins in vivo, we expressed GFP-tagged versions of the four rat PC espin isoforms by transient transfection in cells of the mouse Neuro-2a neuroblastoma line. We did not detect endogenous espins in these cells using espin antibody. The results were similar for the four rat PC isoforms, so only examples of rat PC espin 1 are shown in Figure $6 A-F$. When examined at times after transfection ranging from 8 to $48 \mathrm{hr}$, the GFP-PC espins were colocalized with F-actin. At early times after transfection ( $8 \mathrm{hr}$ ), when levels of the GFP-PC espins were still relatively low, the GFP-PC espins

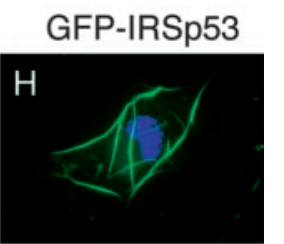

were localized to spiky, F-actin-rich projections (filopodia) and arcs beneath some concave cell margins (Fig. 6A,B). As the time after transfection and level of GFP-PC espin increased, the GFP-PC espins and F-actin remained colocalized, but the labeling of filopodia decreased as espin-rich coarse cytoplasmic F-actin bundles became the dominant labeled structure (Fig. 6C,D). These coarse cytoplasmic F-actin bundles were not detected in untransfected control cells (data not shown). A similar effect was noted previously during expression of other espin isoforms in cells of the NRK and BHK fibroblastic lines (Bartles et al., 1996, 1998; Chen et al., 1999) but was more evident in the Neuro-2a cells because they contain fewer actin stress fibers than NRK or BHK cells. In cells displaying a neuronal morphology, the coarse cytoplasmic espin/Factin bundles were frequently present in large neurites (Fig. 6E,F). None of these results depended on the presence of the GFP tag, because identical results were obtained when the PC espin isoforms were expressed in untagged form using the pcDNA3 vector and detected with espin antibody (data not shown).

\section{PC espins in the cerebellar PSD fraction} To obtain independent biochemical verification for the presence of espins in PC PSDs, PSDs were isolated from rat cerebellar homogenate by centrifugation in discontinuous sucrose density gradients using standard procedures. When Western blots containing $1 \mu \mathrm{g}$ of protein from cerebellar homogenate, synaptosomes, and PSD fraction were labeled with espin antibody, a dramatic enrichment of PC espins was observed in the PSD fraction (Fig. 7A). The extent of enrichment observed for the PC espins was similar to that noted for a known protein of the PC PSD (Brenman et al., 1996), the membrane-associated guanylate kinase PSD-93/chapsyn-110 (Fig. 7A). The weak band positioned immediately beneath the espin band in the synaptosome lane was attributable to nonspecific binding and was not evident on the Western blot containing $30 \mu \mathrm{g}$ of protein (Fig. $7 A$ ). We next checked to see whether PC espins fractionated like "core" proteins of the PSD, as defined operationally by resistance to extraction with 3\% n-laurylsarcosine (Cho et al., 1992). PSDs isolated from rat cerebellum by a single extraction with $0.5 \%$ Triton X-100 were subjected to a second extraction step involving buffer alone, $0.5 \%$ Triton X-100, or 3\% $n$-laurylsarcosine. The $\mathrm{PC}$ espins remained associated with the PSD fraction after a second extraction in Triton X-100 (Fig. $7 B$ ), suggesting that they were tightly associated with the PSD. However, they were mostly solubilized by $3 \% n$-laurylsarcosine (Fig. $7 B$ ), suggesting that they do not represent core proteins of the PSD. In contrast, PSD93/chapsyn-110 better resisted extraction with 3\% n-laurylsarcosine (Fig. $7 B$ ). The $3 \% n$-laurylsarcosine also extracted the majority of the actin from the PSD fraction (Fig. $7 B$ ). 
A
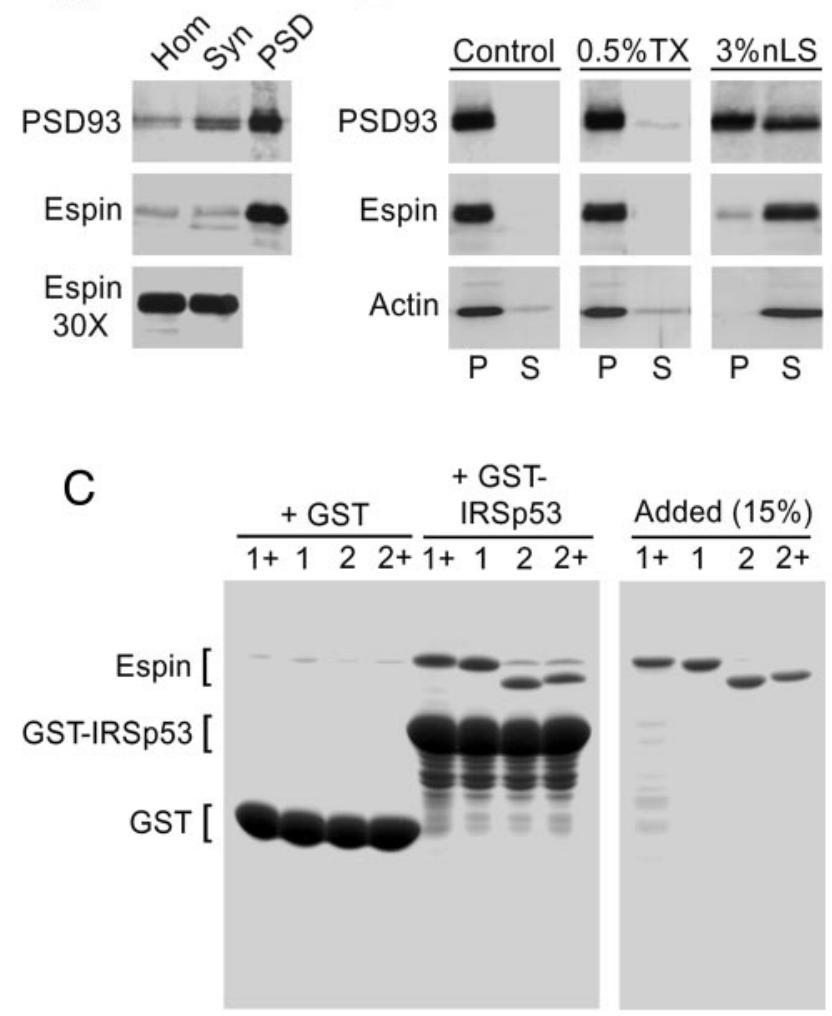

D

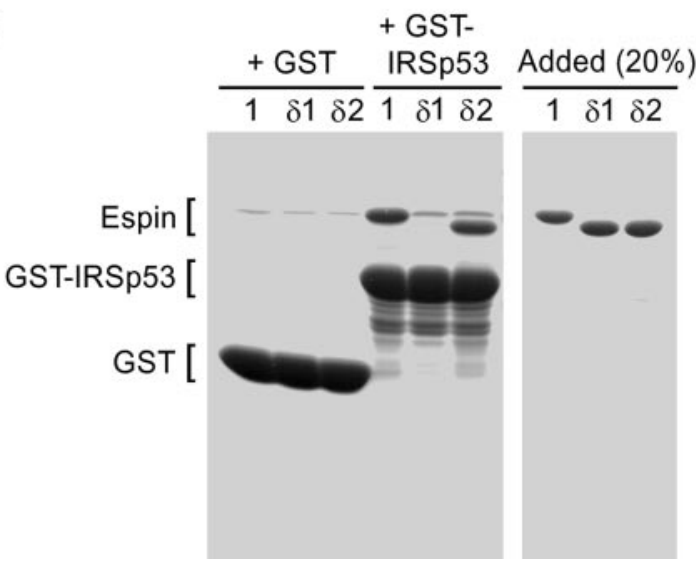

Figure 7. Enrichment of $\mathrm{PC}$ espins in cerebellar PSD fraction and binding to IRSp53 SH3 domain. $A$, Western blots containing $1 \mu \mathrm{g}$ of protein from rat cerebellar homogenate (Hom), synaptosomes (Syn), and PSD fraction (PSD) labeled with antibody to PSD-93/chapsyn-110 (PSD93) or espin (Espin) show a similar high enrichment in the PSD fraction. Note that the synaptosome lane labeled with espin antibody contains a weak, nonspecifically labeled band just below the $\mathrm{PC}$ espin. This band is not evident on the Western blot of homogenate and synaptosomes loaded with $30 \mu \mathrm{g}$ of protein (Espin $30 X)$. B, Western blots of the high-speed pellet $(P)$ and supernatant $(S)$ resulting from the extraction of a rat cerebellar PSD fraction ( 1 Triton X-100 treatment) with HEPES-buffered $0.32 \mathrm{~m}$ sucrose (Control), $0.5 \%$ Triton X-100 in $150 \mathrm{~mm} \mathrm{KCl}(0.5 \% T X)$, or 3\% n-laurylsarcosine (3\%nLS) are labeled with antibody to PSD-93/ chapsyn-110 (PSD93), espin (Espin), or actin (Actin). All three proteins remain predominantly in the pellet during extraction with the $0.5 \%$ Triton X-100 in $150 \mathrm{~mm} \mathrm{KCl}$, but the PC espin and the actin are primarily extracted by $3 \% n$-laurylsarcosine, suggesting that, although tightly associated with the PSD, they do not represent "core" components. C, D, Coomassie blue-stained SDS gels showing binding to IRSp53 SH3 domain peptide. The positions of the PC espin proteins (Espin), the GST-IRSp53 SH3 domain fusion protein (GST-IRSp53), and GST alone (GST) in the gels are designated by brackets at the left. C, Gel of washed bead pellets resulting from a pull-down assay showing that all four rat $\mathrm{PC}$ espin isoforms $(1+, 1,2$, or $2+)$ bind to glutathione-Sepharose beads loaded with GST-IRSp53 SH3 domain fusion protein

\section{Interaction between the PC espins and IRSp53}

We obtained evidence for a direct binding interaction between PC espins and IRSp53, an SH3 adapter and known regulator of the actin cytoskeleton (Krugmann et al., 2001; Miki and Takenawa, 2002) that has been localized previously to PC PSDs (Abbott et al., 1999). The $\mathrm{N}$-terminal portion of PC espin 1, including its two proline-rich peptides, was used as bait in a yeast twohybrid screen to identify candidate espin-binding proteins in commercial mouse brain and testis cDNA libraries. Of the 35 positive clones obtained in two independent screens, seven were overlapping clones of the short form of mouse IRSp53 (GenBank accession number BC016411). The inserts ranged in size from 1.8 to $2.5 \mathrm{~kb}$. All encoded the C-terminal half of IRSp53, which contained its SH3 domain (Yeh et al., 1998; Krugmann et al., 2001; Miki and Takenawa, 2002) and included the 3'-UTR. The longest clone was nearly full length, starting at A49. To confirm this binding interaction in mammalian cells, we expressed this longest IRSp53 construct as a GFP fusion in the presence of untagged versions of the rat $\mathrm{PC}$ espins in transiently cotransfected mouse Neuro-2a neuroblastoma cells. Regardless of PC espin isoform, the GFP-IRSp53 colocalized with the espin-rich coarse cytoplasmic F-actin bundles shown previously (Fig. $6 C, D$ ) to be elicted by expression of the PC espins. This result is illustrated for rat PC espin 1 in Figure $6, G$ and $H$. This interaction required the $\mathrm{N}$-terminal proline-rich peptide of the PC espins. Deletion of either proline-rich peptide from the PC espins had no effect on the ability to elicit the formation of coarse cytoplasmic F-actin bundles (Fig. 6, compare $G, I$, and $K$ with control in $M$ ) or to become colocalized with the F-actin bundles (data not shown). When expressed in the presence of PC espins that were missing the C-terminal proline-rich peptide ( 82 ), the GFP-IRSp53 maintained its colocalization with the coarse cytoplasmic espin/Factin bundles (Fig. $6 I, J$ ). In contrast, deletion of the $\mathrm{N}$-terminal proline-rich peptide of the PC espins $(\delta 1)$ eliminated the binding of GFP-IRSp53 to the espin/F-actin bundles. Instead, the GFPIRSp53 showed lower levels of accumulation and localization to a dense aggregate, possibly an aggresome (Kopito, 2000), in the perinuclear region (Fig. $6 K, L$ ). This was the same pattern of localization observed for the GFP-IRSp53 when it was expressed in the absence of the PC espins (Fig. $6 \mathrm{M}, N$ ). These results suggested that the N-terminal proline-rich peptide of the PC espins bound IRSp53, presumably through its $\mathrm{SH} 3$ domain.

The direct nature of this interaction between the PC espins and the SH3 domain-containing C-terminal peptide of IRSp53 was confirmed in vitro using pull-down assays. When glutathione-Sepharose beads loaded with GST-IRSp53 SH3 domain fusion protein or GST alone were incubated with the PC espin isoforms, relatively large amounts of the espins bound to the GST-IRSp53 beads but not to the GST control beads (Fig. 7C). All bead pellet samples contained minor amounts of a bac-

\footnotetext{
(+GST-IRSp53) but not to those loaded with an equivalent amount of GST alone (+GST). Right, Gel showing $15 \%$ of the amount of the rat $\mathrm{PC}$ espin isoforms added in the assay [Added (15\%)]. D, Gel of washed bead pellets resulting from a pull-down assay showing that rat $P C$ espin $1(1)$ and rat $P C$ espin 1 missing its C-terminal proline-rich peptide $(\delta 2)$ bind to glutathione-Sepharose beads loaded with GST-IRSp53 SH3 domain fusion protein (+ GSTIRSp53) but not to those loaded with GST alone (+GST). In contrast, rat PC espin 1 missing its $\mathrm{N}$-terminal proline-rich peptide $(\delta 1)$ does not bind to the beads loaded with GST-IRSp53 SH3 domain fusion protein. Right, Gel showing $20 \%$ of the amount of the PC espin 1 constructs added in the assay [Added (20\%)]. Note that, in both $C$ and $D$, the washed bead pellets contain small amounts of a bacterial protein that comigrates with rat $\mathrm{PC}$ espins 1 and $1+$ and is contributed by the loaded beads and not the PC espin constructs.
} 
terial protein that comigrated with PC espins 1 and $1+$ and was contributed by the beads loaded with GST or GST-IRSp53 SH3 domain not the PC espins. Additional pull-down assays comparing equivalent amounts of PC espin 1 and PC espin 1 missing either its $\mathrm{N}$-terminal or C-terminal proline-rich peptide confirmed the involvement of the $\mathrm{N}$-terminal proline-rich peptide. PC espin 1 and PC espin 1 missing its C-terminal proline-rich peptide $(\delta 2)$ bound to the beads at high levels (Fig. 7D). However, deletion of the $\mathrm{N}$-terminal proline-rich peptide of PC espin $1(\delta 1)$ decreased the level of binding to the low background levels noted for beads loaded with GST alone (Fig. 7B).

\section{Discussion}

We localized espins to PCs in the cerebellar cortex of mouse and rat and identified four novel espin isoforms in these neurons. These espins are enriched in PC dendritic spines and are not detected in other spiny neurons of the CNS. The PC espins exhibit the properties of modular actin-bundling proteins that could efficiently cross-link the actin cytoskeleton in PC dendritic spines and/or mediate its connection to the PSD by binding SH3 adapter proteins. The PC espins show no obvious relationship to other modular actin-binding proteins, such as spinophilin/ neurabin-II, synaptopodin, or $\alpha$-actinin-2, that are present in the dendritic spines of other brain regions but are either absent or expressed at low levels in PCs (Allen et al., 1997; Mundel et al., 1997; Satoh et al., 1998; Wyszynski et al., 1998; Deller et al., 2000).

Previously, espins have been detected only in epithelial cells (Bartles et al., 1996, 1998; Zheng et al., 2000). Thus, this first report of espins in neurons indicates that the espin family of actin-binding-bundling proteins has a wider cell-type distribution than originally appreciated. Although novel in sequence, the $\mathrm{PC}$ espin isoforms fit the established pattern for espin isoform structure (Bartles, 2000): they contain the C-terminal peptide shared by all known isoforms, but they differ from other espin isoforms in the $\mathrm{N}$-terminal peptides that are connected to the shared C-terminal peptide. A PC-specific site for transcriptional initiation specifies espin isoforms that resemble superficially a truncated version of the $\sim 110 \mathrm{kDa}$ Sertoli cell espin missing its $\mathrm{N}$-terminal ankyrin repeats (Bartles et al., 1996). However, the situation is further complicated by differential splicing, which, through the differential use of exons $q$ and s, accounts for a total of four sequence permutations. The significance of these differences in splicing with regard to isoform localization or function remains to be established.

All four PC espin isoforms contain the espin C-terminal peptide, which is believed to include at least two F-actin-binding sites and is both necessary and sufficient for espin-mediated actinbundling activity in vitro (Bartles et al., 1998). All four PC espin isoforms also contain a third F-actin-binding site, the additional F-actin-binding site encoded by exon o (Chen et al., 1999). Accordingly, all four PC espins appear as efficient as Sertoli cell espin constructs at binding and bundling actin filaments in vitro (Chen et al., 1999). In view of the high activity they demonstrate in actin-bundling assays and their structural similarity to the $\Delta \mathrm{N} 338$ truncated version of Sertoli cell espin characterized previously in quantitative binding assays (Chen et al., 1999), it is likely that PC espins also bind F-actin with $K_{\mathrm{d}}$ values in the 50 $100 \mathrm{~nm}$ range. This affinity is one to two orders of magnitude greater than that observed for many other actin-binding and actin-cross-linking proteins (Bartles, 2000). These observations lead naturally to the hypothesis that the PC espins function in part to cross-link actin filaments in PC spines in situ.

Light and electron microscopic immunocytochemistry dem- onstrates that the PC espins are enriched in dendritic spines, although they are distributed to some extent throughout the somatodendritic compartment of the PC. Compared with the parallel actin bundles in which other espin isoforms have been localized (Bartles, 2000; Zheng et al., 2000), the actin filaments of dendritic spines appear sparse, less organized, and more dynamic (Landis and Reese, 1983; Hirokawa, 1989; Fischer et al., 1998, 2000; Matus, 2000; Colicos et al., 2001; Star et al., 2002). Nevertheless, the PC espins could still perform an actin cross-linking function and, thereby, stabilize the actin cytoskeleton of PC dendritic spines. This could help explain why PC cell spines appear relatively similar in size and shape (Strata et al., 2000) and uniformly rich in F-actin (Capani et al., 2001). A stabilizing effect on the actin cytoskeleton might also help explain what appears to be a unique attribute of PC spines: the ability to grow and/or to be retained in the absence of afferents (Hirano et al., 1977; Takács et al., 1997; Bravin et al., 1999).

When expressed in transfected cells, the PC espins consistently elicit the formation of coarse cytoplasmic F-actin bundles and appear to increase the levels of F-actin. These effects were noted previously in transfected fibroblastic cells expressing espins (Bartles et al., 1996, 1998; Chen et al., 1999). It is unclear whether the increase in the level of F-actin reflects an upregulation of actin synthesis in response to the creation of an espin cross-linked actin bundle "sink" for actin monomer (Lyubimova et al., 1999) or whether espins might also somehow stimulate actin polymerization.

One characteristic property of the espins is that their actinbundling activity is not inhibited by $\mathrm{Ca}^{2+}$. To account for the degeneration of the parallel actin bundles in the hair cell stereocilia of espin-deficient homozygous jerker mice, we postulated that espin cross-links stabilize the actin bundles against the transient local increases in $\mathrm{Ca}^{2+}$ that accompany mechanoelectrical signal transduction in hair cell stereocilia (Zheng et al., 2000). Dendritic spines are known to experience transient local increases in $\mathrm{Ca}^{2+}$ concentration during synaptic transmission (Holthoff et al., 2002; Nimchinsky et al., 2002; Segal, 2002). Depending on assay system and conditions, increases in $\mathrm{Ca}^{2+}$ concentration have been reported to reduce spine motility (Fischer et al., 2000), decrease the fraction of dynamic spine actin (Star et al., 2002), and, at higher concentrations, elicit the selective loss of F-actin from spines (Halpain et al., 1998). PC dendritic spines experience large activity-dependent increases in the concentration of $\mathrm{Ca}^{2+}$ through voltage-dependent entry and inositol1,4,5-trisphosphate-mediated release from intracellular stores (Finch and Augustine, 1998; Wang et al., 2000; Okubo et al., 2001). In fact, these increases in $\mathrm{Ca}^{2+}$ concentration are correlated with cerebellar long-term depression and motor learning (Wang et al., 2000; Hansel et al., 2001). Thus, it is possible that espins may also help protect the actin cytoskeleton of PC spines from the excitotoxic effects associated with these large increases in $\mathrm{Ca}^{2+}$ concentration. We are currently examining the structure and function of PCs in jerker mice to determine whether they show defects in morphology, electrophysiology, or dynamics.

Our immunocytochemical evidence suggests a close association between the PC espins and the PSD and explains why PC espins are so highly enriched in cerebellar PSD fractions. It is unclear whether this association is mediated by direct binding between the PC espins and PSD-associated actin filaments (Matus et al., 1982; Landis and Reese, 1983; Hirokawa, 1989) or whether the PC espins bind PSD proteins other than actin. Representatives of $>70$ families of proteins have been identified in dendritic spines and PSDs (Husi et al., 2000; Kennedy, 2000; 
Scannevin and Huganir, 2000; Zhang and Benson, 2000; Hering and Sheng, 2001). Among these are proteins that interact with actin filaments indirectly as members of signaling cascades or multiprotein adapter complexes. It is possible that the PC espins bind such proteins via domains believed not to participate directly in binding F-actin. Promising candidates include the two proline-rich peptides of the PC espins. We identified IRSp53 as an $\mathrm{SH} 3$ adapter protein that binds to the $\mathrm{N}$-terminal proline-rich peptide of the PC espins in vivo and in vitro. This interaction may be physiologically relevant, because IRSp53 has been localized previously to PC PSDs. IRSp53 mRNA and protein are moderately abundant in rat cerebellum, and, among cerebellar cell types, high levels of transcript are detected only in PCs (Abbott et al., 1999; Thomas et al., 2001). Moreover, the IRSp53 protein has been shown to be highly enriched in rat cerebellar PSD fractions and, when localized by immunofluorescence, to be concentrated at synapses distributed densely throughout the molecular layer of the cerebellar cortex (Abbott et al., 1999). IRSp53 has been identified independently as a substrate for the insulin receptor tyrosine kinase (Yeh et al., 1996) and as a protein ligand for brain angiogenesis inhibitor 1 (Oda et al., 1999) and for atrophin-1, the product of the dentatorubral-pallidoluysian atrophy gene (Okamura-Oho et al., 1999). It is unclear how IRSp53 is tied to signaling by insulin or insulin-like growth factors in the brain, but recent discoveries suggest that IRSp53 can regulate the actin cytoskeleton. During binding Cdc42 to its partial Cdc42- and Rac-interactive binding (CRIB) domain, IRSp53 avails its SH3 domain for binding the Ena/VASP (vasodilator-stimulated phosphoprotein) family member Mena, and the two proteins appear to act synergistically to promote the formation of F-actin-rich filopodia or neurites (Govind et al., 2001; Krugmann et al., 2001). Conversely, WAVE2, a nucleation-promoting factor for Arp2/3mediated actin polymerization, can bind the $\mathrm{SH} 3$ domain of IRSp53 and thereby enhance the binding of Rac to its CRIB domain (Miki and Takenawa, 2002). Rac is known to regulate the numbers and sizes of PC dendritic spines (Luo et al., 1996; Nakayama et al., 2000; Tashiro et al., 2000). Thus, in addition to affecting the organization and dynamics of PC dendritic spines directly, the PC espins may influence these parameters indirectly through their participation in a multiprotein scaffold that contains IRSp53 or other SH3 adapter proteins. The existence of an alternate multiprotein scaffold in the PC PSD may explain why PSD-93 knock-out mice fail to show structural or functional abnormalities (McGee et al., 2001).

\section{References}

Abbott M-A, Wells DG, Fallon JR (1999) The insulin receptor tyrosine kinase substrate p58/53 and the insulin receptor are components of CNS synapses. J Neurosci 19:7300-7308.

Alicea HA, Mooseker MS (1988) Characterization of villin from the intestinal brush border of the rat, and comparative analysis with avian villin. Cell Motil Cytoskel 9:60-72.

Allen PB, Ouimet CC, Greengard P (1997) Spinophilin, a novel protein phosphatase 1 binding protein localized to dendritic spines. Proc Natl Acad Sci USA 94:9956-9961.

Araki K, Meguro H, Kushiya E, Takayama C, Inoue Y, Mishina M (1993) Selective expression of the glutamate receptor channel $\delta 2$ subunit in cerebellar Purkinje cells. Biochem Biophys Res Commun 197:1267-1276.

Bartles JR (2000) Parallel actin bundles and their multiple actin-bundling proteins. Curr Opin Cell Biol 12:72-78.

Bartles JR, Wierda A, Zheng L (1996) Identification and characterization of espin, an actin-binding protein localized to the F-actin-rich junctional plaques of Sertoli cell ectoplasmic specializations. J Cell Sci 109:1229-1239.

Bartles JR, Zheng L, Li A, Wierda A, Chen B (1998) Small espin: a third actin-bundling protein and potential forked protein ortholog in brush border microvilli. J Cell Biol 143:107-119.

Bravin M, Morando L, Vecelli A, Rossi F, Strata P (1999) Control of spine formation by electrical activity in the adult rat cerebellum. Proc Natl Acad Sci USA 96:1704-1709.

Brenman JE, Christopherson KS, Craven SE, McGee AW, Bredt DS (1996) Cloning and characterization of postsynaptic density 93, a nitric oxide synthase interacting protein. J Neurosci 16:7407-7415.

Capani F, Martone ME, Deerinck TJ, Ellisman MH (2001) Selective localization of high concentrations of F-actin in subpopulations of dendritic spines in the rat central nervous system: a three-dimensional electron microscopic study. J Comp Neurol 435:156-170.

Carlin RK, Grab DJ, Cohen RS, Siekevitz P (1980) Isolation and characterization of postsynaptic densities from various brain regions: enrichment of different types of postsynaptic densities. J Cell Biol 86:831-843.

Chen B, Li A, Wang D, Wang M, Zheng L, Bartles JR (1999) Espin contains an additional actin-binding site in its $\mathrm{N}$ terminus and is a major actinbundling protein of the Sertoli cell-spermatid ectoplasmic specialization junctional plaque. Mol Biol Cell 10:4327-4339.

Cho K-O, Hunt CA, Kennedy MB (1992) The rat brain postsynaptic density fraction contains a homolog of the Drosophila discs-large tumor suppressor protein. Neuron 9:929-942.

Colicos MA, Collins BE, Sailor MJ, Goda Y (2001) Remodeling of synaptic actin induced by photoconductive stimulation. Cell 107:605-616.

De Camilli P, Chen H, Hyman J, Panepucci E, Bateman A, Brunger AT (2002) The ENTH domain. FEBS Lett 513:11-18.

Deller T, Merten T, Roth SU, Mundel P, Frotscher M (2000) Actinassociated protein synaptopodin in the rat hippocampal formation: localization in the spine neck and close association with the spine apparatus of principal neurons. J Comp Neurol 418:164-181.

Dosemeci A, Reese T (1993) Inhibition of endogenous phosphatase in a postsynaptic density fraction allows extensive phosphorylation of the major postsynaptic density protein. J Neurochem 61:550-555.

Dunaevsky A, Tashiro A, Majewska A, Mason C, Yuste R (1999) Developmental regulation of spine motility in the mammalian central nervous system. Proc Natl Acad Sci USA 96:13438-13443.

Finch EA, Augustine GJ (1998) Local calcium signalling by inositol-1, 4, 5-trisphosphate in Purkinje cell dendrites. Nature 396:753-756.

Fischer M, Kaech S, Knutti D, Matus A (1998) Rapid actin-based plasticity in dendritic spines. Neuron 20:847-854.

Fischer M, Kaech S, Wagner U, Brinkhaus H, Matus A (2000) Glutamate receptors regulate actin-based plasticity in dendritic spines. Nat Neurosci 3:887-894.

Glenney Jr JR, Kaulfus P, Matsudaira P, Weber K (1981) F-actin binding and bundling properties of fimbrin, a major cytoskeletal protein of microvillus core filaments. J Biol Chem 256:9283-9288.

Govind S, Kozma R, Monfries C, Lim L, Ahmed S (2001) Cdc42Hs facilitates cytoskeletal reorganization and neurite outgrowth by localizing the $58-\mathrm{kDa}$ insulin receptor substrate to filamentous actin. J Cell Biol 152:579-594.

Halpain S, Hipolito A, Saffer L (1998) Regulation of F-actin stability in dendritic spines by glutamate receptors and calcineurin. J Neurosci 18:9835-9844.

Hansel C, Linden DJ, D’Angelo E (2001) Beyond parallel fiber LTD: the diversity of synaptic and non-synaptic plasticity in the cerebellum. Nat Neurosci 4:467-475.

Hering H, Sheng M (2001) Dendritic spines: structure, dynamics and regulation. Nat Rev Neurosci 2:880-888.

Hirano A, Dembitzer HM, Yoon CH (1977) Development of Purkinje cell somatic spines in the weaver mouse. Acta Neuropathol 40:85-90.

Hirokawa R (1989) The arrangement of actin filaments in the postsynaptic cytoplasm of the cerebellar cortex revealed by quick-freeze deep-etch electron microscopy. Neurosci Res 6:269-275.

Holthoff K, Tsay D, Yuste R (2002) Calcium dynamics of spines depend on their dendritic location. Neuron 33:425-437.

Houk JC, Mugnaini E (2002) Cerebellum. In: Fundamental neuroscience (Squire LR, Bloom FE, McConnell SK, Roberts JL, Spitzer NC, Zigmond MJ, eds), pp 841-872. San Diego: Academic.

Husi H, Ward MA, Choudhary JS, Blackstock WP, Grant SG (2000) Proteomic analysis of NMDA receptor-adhesion protein signaling complexes. Nat Neurosci 3:661-669. 
Kennedy MB (2000) Signal-processing machines at the postsynaptic density. Science 290:750-754.

Kopito RR (2000) Aggresomes, inclusion bodies and protein aggregation. Trends Cell Biol 10:525-530.

Korkortian E, Segal M (2001) Regulation of dendritic spine motility in cultured hippocampal neurons. J Neurosci 21:6115-6124.

Krugmann S, Jordens I, Gevaert K, Driessens M, Vandekerchove J, Hall A (2001) Cdc42 induces filopodia by promoting the formation of an IRSp53:Mena complex. Curr Biol 11:1645-1655.

Landis DM, Reese T (1983) Cytoplasmic organization in cerebellar dendritic spines. J Cell Biol 97:1169-1178.

Landsend AS, Amiry-Moghaddam M, Maatsubara A, Bergersen L, Usami S, Wenthold RJ, Ottersen OP (1997) Differential localization of $\delta$ glutamate receptors in the rat cerebellum: coexpression with AMPA receptors in parallel fiber-spine synapses and absence from climbing fiber-spine synapses. J Neurosci 17:834-842.

Lin CS, Shen W, Chen ZP, Tu YH, Matsudaira P (1994) Identification and characterization of I-plastin, a human fimbrin isoform expressed in intestine and kidney. Mol Cell Biol 14:2457-2467.

Luo L, Hensch TK, Ackerman L, Barbel S, Jan LY, Jan YN (1996) Differential effects of the Rac GTPase on Purkinje cell axons and dendritic trunks and spines. Nature 379:837-840.

Lyubimova A, Bershadsky AD, Ben-Ze'ev A (1999) Autoregulation of actin synthesis requires the $3^{\prime}$-UTR of actin mRNA and protects cells from actin overproduction. J Cell Biochem 76:1-12.

Matus A (2000) Actin-based plasticity in dendritic spines. Science 290:754-758.

Matus A, Ackermann M, Pehling G, Byers HR, Fujiwara K (1982) High actin concentrations in brain dendritic spines and postsynaptic densities. Proc Natl Acad Sci USA 79:7590-7594.

McGee AW, Topinka JR, Hashimoto K, Petralia RS, Kakizawa S, Kauer F, Aguilera-Moreno A, Wenthold RJ, Kano M, Bredt DS (2001) PSD-93 knock-out mice reveal that neuronal MAGUKs are not required for development or function of parallel fiber synapses in cerebellum. J Neurosci 21:3085-3091.

Miki H, Takenawa T (2002) WAVE2 serves a functional partner of IRSp53 by regulating its interaction with Rac. Biochem Biophys Res Commun 293:93-99.

Miyagi Y, Yamashita T, Masahiro F, Sonoda T, Okuno T, Yamada K, Watanabe M, Nagashima Y, Aoki I, Okuda K, Mishina M, Kawamoto S (2002) Delphilin: a novel PDZ and formin homology domaincontaining protein that synaptically colocalizes and interacts with glutamate receptor $\delta 2$ subunit. J Neurosci 22:803-814.

Molinari M, Filippini V, Leggio MG (2002) Neuronal plasticity of interrelated cerebellar and cortical networks. Neuroscience 111:863-870.

Mundel P, Heid HW, Mundel TM, Kruger M, Reiser J, Kreiz W (1997) Synaptopodin: an actin-associated protein in telecephalic dendrites and renal podocytes. J Cell Biol 139:193-204.

Nakayama AY, Harms MB, Luo L (2000) Small GTPases Rac and Rho in the maintenance of dendritic spines and branches in hippocampal pyramidal neurons. J Neurosci 20:5329-5338.

Namba Y, Ito M, Zu Y, Shigesada K, Maruyama K (1992) Human T-cell L-plastin bundles actin filaments in a calcium-dependent manner. J Biochem 112:503-507.

Nimchinsky EA, Sabatini BL, Svoboda K (2002) Structure and function of dendritic spines. Annu Rev Physiol 64:313-353.

Oda K, Shiratsuchi T, Nishimori H, Inazawa J, Yoshikawa, Taketani Y, Nakamura Y, Tokino T (1999) Identification of BAIAP2 (BAI-associated protein 2), a novel human homologue of hamster IRSp53, whose SH3 domain interacts with the cytoplasmic domain of BAI1. Cytogenet Cell Genet 84:75-82.

Okamura-Oho Y, Miyashita T, Ohmi K, Yamada M (1999) Dentatorubralpallidoluysian atrophy protein interacts through a proline-rich region near polyglutamine with the $\mathrm{SH} 3$ domain of an insulin receptor tyrosine kinase substrate. Hum Mol Genet 8:947-957.

Okubo Y, Kakizawa S, Hirose K, Iino M (2001) Visualization of IP $_{3}$ dynamics reveals a novel AMPA receptor-triggered $\mathrm{IP}_{3}$ production pathway mediated by voltage-dependent $\mathrm{Ca}^{2+}$ influx in Purkinje cells. Neuron 32:113-122.

Roche KW, Ly CD, Petralia RS, Wang Y-X, McGee AW, Bredt DS, Wenthold RJ (1999) Postsynaptic density- 93 interacts with the $\delta 2$ glutamate receptor subunit at parallel fiber synapses. J Neurosci 19:3926-3934.

Satoh A, Nakanishi H, Obaishi H, Wada M, Takahashi K, Satoh K, Hirao K, Nishioka H, Hata Y, Mizoguchi A, Takai Y (1998) Neurabin-II/spinophilin. An actin filament-binding protein with one PDZ domain localized at cadherin-based cell-cell adhesion sites. J Biol Chem 273:3470-3475.

Scannevin RH, Huganir RL (2000) Postsynaptic organization and regulation of excitatory synapses. Nat Rev Neurosci 1:133-141.

Segal M (2002) Changing views of Cajal's neuron: the case of the dendritic spine. Prog Brain Res 136:101-107.

Sheng M (2001) Molecular organization of the postsynaptic specialization. Proc Natl Acad Sci USA 98:7058-7061.

Star EN, Kwiatkowski DJ, Murthy VN (2002) Rapid turnover of actin in dendritic spines and its regulation by activity. Nat Neurosci 5:239-246.

Strata P, Morando L, Bravin M, Rossi F (2000) Dendritic spine density in Purkinje cells. Trends Neurosci 23:53-57.

Takács J, Gombos G, Görcs T, Becker T, de Barry J, Hámori J (1997) Distribution of metabotropic glutamate receptor type la in Purkinje cell dendritic spines is independent of the presence of presynaptic parallel fibers. J Neurosci Res 50:433-442.

Tashiro A, Minden A, Yuste R (2000) Regulation of dendritic spine morphology by the Rho family of small GTPases: antagonistic roles of Rac and Rho. Cereb Cortex 10:927-938.

Thomas EA, Foye PE, Alvarez CE, Usui H, Sutcliffe JG (2001) Insulin receptor substrate protein $\mathrm{p} 53$ localization in rats suggests mechanism for specific polyglutamine neurodegeneration. Neurosci Lett 309:145-148.

Wang SS-H, Denk W, Häusser M (2000) Coincidence detection in single dendritic spines mediated by calcium release. Nat Neurosci 3:1266-1273.

Wu G, Fang Y, Lu ZH, Ledeen RW (1998) Induction of axon-like and dendrite-like processes in neuroblastoma cells. J Neurocytol 27:1-14.

Wyszynski M, Kharazia V, Shanghvi R, Rao A, Beggs AH, Craig AM, Weinberg R, Sheng M (1998) Differential regional expression and ultrastructural localization of alpha-actinin-2, a putative NMDA receptoranchoring protein, in rat brain. J Neurosci 18:1383-1392.

Yeh TC, Ogawa W, Danielsen AG, Roth RA (1996) Characterization and cloning of a $58 / 53-\mathrm{kDa}$ substrate of the insulin receptor tyrosine kinase. J Biol Chem 271:2921-2928.

Yeh TC, Li W, Keller G-A, Roth RA (1998) Disruption of a putative SH3 domain and the proline-rich motifs in the 53-kDa substrate of the insulin receptor kinase does not alter its subcellular localization of ability to serve as a substrate. J Cell Biochem 68:139-150.

Zhang W, Benson DL (2000) Development and molecular organization of dendritic spines and their synapses. Hippocampus 10:512-526.

Zheng L, Sekerkova G, Vranich K, Tilney LG, Mugnaini E, Bartles JR (2000) The deaf jerker mouse has a mutation in the gene encoding the espin actin-bundling proteins of hair cell stereocilia and lacks espins. Cell 102: $377-385$. 